\title{
Development of a time-resolved fluorometry based immunoassay for the determination of canine haptoglobin in various body fluids
}

\author{
María Dolores PARRA ${ }^{a}$, Ville VÄISÄNEN ${ }^{b}$, José Joaquín CERÓN ${ }^{a *}$ \\ ${ }^{a}$ Department of Animal Medicine and Surgery, Faculty of Veterinary Medicine, University of Murcia, \\ 30100 Espinardo Campus Murcia, Spain \\ b Department of Biotechnology, University of Turku, 20520 Turku, Finland
}

(Received 6 May 2004; accepted 7 September 2004)

\begin{abstract}
A time-resolved immunofluorometric assay (TR-IFMA) was developed for the determination of haptoglobin (Hp) in canine serum. Haptoglobin was purified from canine acute phase serum by ammonium sulphate precipitation followed by gel filtration. This isolated dog $\mathrm{Hp}$ was used as the standard to calibrate the assay. Intra- and inter-assay coefficients of variation of the assay were, respectively, $5.7 \%$ and $16.6 \%$ at $0.51 \mathrm{mg} / \mathrm{mL}, 2.4 \%$ and $10.6 \%$ at $2.1 \mathrm{mg} / \mathrm{mL}$ and $10.5 \%$ and $11.9 \%$ at $32.5 \mathrm{mg} / \mathrm{mL}$. The dilution of serum samples with high $\mathrm{Hp}$ concentrations resulted in linear regression equations with $R^{2}$ of 0.99 and 0.97. A high correlation was found in serum Hp measurements by TR-IFMA and a commercial assay based on peroxidase activity of haemoglobin bound to haptoglobin $\left(R^{2}=0.96\right)$. The limit of detection for the TR-IFMA method was $0.002 \mu \mathrm{g} / \mathrm{mL}$. The addition of fresh haemolysate to serum samples did not affect the haptoglobin concentration $(P=0.694)$. Statistical differences $(P<0.003)$ were found between healthy dogs and dogs with different pathological processes. In whole blood, Hp concentrations were much lower than in serum but closely related $\left(R^{2}=0.84\right)$ whereas saliva Hp concentrations were poorly related with serum concentrations $\left(R^{2}=\right.$ $0.53)$. However, the concentration of $\mathrm{Hp}$ in saliva was significantly $(P<0.039)$ higher in dogs with pathological processes compared to healthy dogs. The assay sensitivity was adequate to also be applied to whole blood and saliva specimens.
\end{abstract}

canine / haptoglobin / time-resolved fluorometry / whole blood / saliva

\section{INTRODUCTION}

Haptoglobin (Hp) is a haemoglobin-binding protein present in the plasma of all vertebrates, and is believed to participate in haemoglobin transport from blood to the liver and recycling of heme iron [22]. Hp, an $\alpha-2$ glycoprotein, is also known as an acute phase protein (APP) in response to a variety of injuries or inflammatory disease states. In veterinary research, measurement of $\mathrm{Hp}$ is particularly important [23] and widely used in assessing the health status of cattle and sheep due to a strong Hp response to infection, with the concentration in the circulation increasing up to 100 -fold or more. In other species, such as humans, dogs, cats and pigs, more modest increases ( 2 to 5 -fold) occur, but these are still sufficient to provide valuable diagnostic information $[6,9]$.

\footnotetext{
* Corresponding author: jjceron@um.es
} 
Canine Hp has been traditionally measured on serum by using non-immunological methods [3] mostly based on the haemoglobin binding capacity of $\mathrm{Hp}[10,20]$ or cyanmethemoglobin binding capacity [31]. Only two immunological methods have been described for determining changes in serum canine $\mathrm{Hp}$, which were adaptations of assays developed for quantifying $\mathrm{Hp} \mathrm{lev-}$ els in humans $[17,38]$. To our knowledge, no reports of canine haptoglobin measurement in other biological fluids such as whole blood or saliva have been described.

Time-resolved fluoroimmunoassays are a non-radioactive label technology which offers rapid and ultrasensitive tests for the measurement of several animal and human hormones [11, 12, 25, 33] and also for the detection of drugs [15], specific antibodies $[1,27]$ and cancer markers [32, 37]. Other possible applications are the determination of acute phase proteins such as bovine haptoglobin [21] or human and canine C-reactive protein [26, 34].

The purpose of this study was the development of a time-resolved immunofluorometric assay (TR-IFMA) for the measurement of $\mathrm{Hp}$ in dog serum and the characterisation of its performance. We also tested the applicability of whole blood and saliva samples for the determination of $\mathrm{Hp}$. Saliva samples can be obtained in a non-invasive method less stressful for the animal and could imply a significant simplification of sample processing.

\section{MATERIALS AND METHODS}

\subsection{Reagents}

The fluorescent Eu-chelate: $N^{1}-(p-$ isothiocyanatobenzyl) diethylenetriamine$N^{1}, N^{2}, N^{3}, N^{4}$-tetraacetic acid-Eu ${ }^{3+}$, biotin isothiocyanate (BITC), microtiter wells coated with streptavidin, DELFIA ${ }^{\circledR}$ Assay Buffer, DELFIA ${ }^{\circledR}$ Wash Solution and DELFIA ${ }^{\circledR}$ Enhancement Solution were purchased from Perkin-Elmer Life Sciences (Wallac Oy,
Turku, Finland). Rabbit anti-human haptoglobin antibodies which cross-react strongly with dog Hp (code No. A0030) were supplied by DAKO (Glostrup, Denmark). The antibody is supplied as the purified immunoglobulin fraction of rabbit antiserum. Molecular weight markers for electrophoresis were from Pharmacia (Finland). The instruments used for measurement - DELFIA ${ }^{\circledR}$ 1234 plate fluorometer and 1235 Automatic Immunoassay System AutoDELFIA - are products of Perkin-Elmer Life Sciences (Wallac Oy, Turku, Finland).

\subsection{Collection of samples}

Serum, whole blood and saliva samples were obtained from 12 healthy dogs supplied by the Animal Center of Murcia University and from 15 sick dogs referred to the Teaching Hospital of the Murcia University Veterinary School.

In order to obtain serum, blood samples were collected by venipuncture into Tapval ${ }^{\circledR}$ tubes (Aquisel; Barcelona, Spain), allowed to clot at room temperature and centrifuged at $3000 \mathrm{~g}$ for $10 \mathrm{~min}$. Serum samples obtained were stored at $-20{ }^{\circ} \mathrm{C}$ until analysis.

Whole blood samples were collected into EDTA tubes (Vacutest Plast, K3 EDTA $0.2 \mathrm{mg} / \mathrm{mL}$; Arzergrande, Italy) and were kept in refrigeration $\left(+4{ }^{\circ} \mathrm{C}\right)$ during the whole study.

For collecting saliva, commercial Salivette tubes (Sarstedt, Aktiengesellschaft \& Co., Nümbrecht, Germany) were used, where cotton wool swabs were replaced by the sponge. The sponge was kept in the dogs' mouth, next to the cheek mucosa for 1$2 \mathrm{~min}$, then returned to the Salivette device and centrifuged during $10 \mathrm{~min}$ at $7000 \mathrm{rpm}$. Finally saliva samples were transferred to eppendorf tubes and stored frozen at $-20^{\circ} \mathrm{C}$.

\subsection{Haptoglobin purification}

The purification of haptoglobin requires a high amount of blood with very high haptoglobin concentration obtained from controlled animals. Therefore a clinically healthy 
dog was conditioned to acute phase inflammation by subcutaneous injection with $1.5 \mathrm{~mL}$ of turpentine. This procedure has been previously followed in the literature to induce an acute phase reaction $[5,16]$ and had the approval of the Murcia University Ethical Committee. Three days later, blood samples were collected by venipuncture. After bleeding the dog, corticosteroids and antibiotics were administered and the dog was under complete clinical monitoring until total recovery was observed. Three millilitres of the serum rich in $\mathrm{Hp}$ was fractionated by 50 $70 \%$ saturated ammonium sulphate [35]. The precipitate was collected by centrifugation $\left(3000 \mathrm{~g}, 30 \mathrm{~min}, 0^{\circ} \mathrm{C}\right)$ and dissolved in $0.9 \% \mathrm{NaCl}$. Ammonium sulphate was removed using PD-10 desalting columns (Amersham Biosciences). Then, the solution was concentrated by Centricon ${ }^{\circledR}$ (4000 rpm, $10{ }^{\circ} \mathrm{C}$ for $2 \mathrm{~h}$ ) and filtered through a $0.22 \mu \mathrm{m}$ pore-size filter (Millipore, Carrigtwohill, Co. Cork, Ireland). The final solution (1 mL) was applied to a Superdex 200 HR column (Amersham Biosciences, Uppsala, Sweden), equilibrated and run with Tris- $\mathrm{HCl}$ containing $150 \mathrm{mM} \mathrm{NaCl}$ and $0.02 \% \mathrm{NaN}_{3}$ (TSA), pH 7.5 with a flow rate of $20 \mathrm{~mL} / \mathrm{h}$. Fractions containing higher protein concentration (the presence of $\mathrm{Hp}$ was confirmed by monitoring activity with a TR-IFMA calibrated with serum rich in $\mathrm{Hp}$ ) were pooled, concentrated by Centricon ${ }^{\circledR}$ (4000 rpm, $10{ }^{\circ} \mathrm{C}$ for $1 \mathrm{~h}$ ), filtered and subjected again to gel filtration. The purity of the protein was assessed for homogeneity by SDSPAGE [18] under reducing and non-reducing conditions in $10 \%$ polyacrilamide gels. The gel was stained with silver nitrate. The concentration of purified $\mathrm{Hp}$ was estimated by the colorimetric Biorad protein assay, using bovine serum albumin as the standard, and by measuring absorbance at $280 \mathrm{~nm}$.

\subsection{Labelling of antibodies with europium chelate}

Two milligrammes of rabbit anti-human haptoglobin antibodies were labelled by incubating them with a 20-fold molar excess of Eu-chelate in $50 \mathrm{mM}$ carbonate buffer ( $\mathrm{pH} 9.8$ ) overnight at $4{ }^{\circ} \mathrm{C}$. The free label was removed from labelled antibodies by gel filtration on a Superdex $200 \mathrm{HR}$ column (Amersham Biosciences, Uppsala, Sweden), equilibrated and run with Tris$\mathrm{HCl}$ containing $150 \mathrm{mM} \mathrm{NaCl}$ and $0.02 \%$ $\mathrm{NaN}_{3}$ (TSA), pH 7.5 with a flow rate of $20 \mathrm{~mL} / \mathrm{h}$. Fractions containing the labelled antibodies were pooled and the protein concentration was determined by the BioRad protein assay. Then bovine serum albumin was added to $0.1 \%$ final concentration and the solution was filtered through a $0.22 \mu \mathrm{m}$ pore-size filter (Millipore, Carrigtwohill, Co. Cork, Ireland).

\subsection{Biotinylation of antibodies}

Two milligrammes of rabbit anti-haptoglobin antibodies and a 25-fold molar excess of BITC were mixed in $50 \mathrm{mM}$ carbonate buffer $\mathrm{pH} 9.8$. After $4 \mathrm{~h}$ at room temperature, the reaction was stopped by removing the excess of BITC. The mixture was passed through two NAP-10 columns and one NAP-5 column (Amersham Biosciences) with TSA pH 7.75. Both columns are based on gel filtration, containing Sephadex G-25 as the matrix. Finally, 0.1\% BSA was added.

\subsection{Immunoassay protocol}

Biotinylated rabbit anti-haptoglobin antibodies were pipetted onto streptavidin-coated microtitration wells in $100 \mu \mathrm{L}$ of DELFIA ${ }^{\circledR}$ Assay Buffer together with $25 \mu \mathrm{L}$ of the samples, including standards of known $\mathrm{Hp}$ content $(0.01-10 \mu \mathrm{g} / \mathrm{mL})$. Serum and whole blood samples were previously diluted $1 / 10000$ in assay buffer, while saliva samples were analysed undiluted or diluted 1/10.

Strips were incubated for $1 \mathrm{~h}$ at room temperature and then washed two times with DELFIA ${ }^{\circledR}$ Wash Solution. After washing, $200 \mu \mathrm{L}$ of labelled anti-Hp antibodies (100 ng) were added to each well. The strips were incubated for $1 \mathrm{~h}$ and then were washed again. Finally, $200 \mu \mathrm{L} /$ well of DELFIA ${ }^{\circledR}$ 
Enhancement Solution were added and the strips were incubated for $5 \mathrm{~min}$. The enhanced fluorescence, proportional to the quantity of Hp in the sample, was measured in a VICTOR 1420 multilabel counter (PerkinElmer Lifesciences, Wallac Oy, Turku, Finland).

\subsection{Assay validation}

\subsubsection{Precision}

The intraassay variation was expressed as the coefficient of variation $(\mathrm{CV} \%)$ and was determined by measuring three canine serum samples, with low, medium and high contents of $\mathrm{Hp}$ (from 0.51 to $32.5 \mathrm{mg} / \mathrm{mL}$ ), 10 times in the same analytical run. The inter-assay variation was assessed by measuring the same samples on four different days.

\subsubsection{Accuracy}

Accuracy was evaluated by linearity under dilution. Two canine serum samples with high Hp concentration $(30.9 \mathrm{mg} / \mathrm{mL}$ and $27.4 \mathrm{mg} / \mathrm{mL})$ were serially diluted $(1: 2,1: 4$, $1: 8,1: 16,1: 32)$ in DELFIA ${ }^{\circledR}$ Assay Buffer. Afterwards, curves representing the measured $\mathrm{Hp}$ concentration versus the expected Hp concentration were constructed. Additionally the TR-IFMA results obtained from 22 serum samples from dogs with normal and high levels of Hp were compared with those provided by measuring the same samples with a commercially available haptoglobin kit based on peroxidase activity (Tridelta Development Ltd., Ireland).

\subsubsection{Limit of detection}

The analytical limit of detection was defined as the lowest concentration to deliver a signal equal to the mean response of the zero calibrator diluent (Assay Buffer) plus three standard deviations. Its determination was based on the analysis of 12 samples.

\subsubsection{Effect of adding haemolysate}

The assay was assessed for interference by adding a haemolysate. Haemolysis was produced by freezing red cells at $-20{ }^{\circ} \mathrm{C}$ in order to not incorporate distilled water to the assay. The haemolysate was added to pooled serum at final haemoglobin concentrations of $0.0,0.25,0.5,1.0,2.0$ and $4.0 \mathrm{~g} / \mathrm{dL}$. The haemoglobin concentration was determined by using an automated blood counter (Vet ABC, ABX Diagnostics, Montpellier, France). The DELFIA ${ }^{\circledR}$ Assay Buffer was used to prepare the haemoglobin series.

\subsection{Clinical study}

Sera from 12 healthy dogs and 15 dogs with different pathologies ( 7 positive to leishmaniasis, 1 of them treated with allopurinol during two months, 3 with pyometra, 1 positive to ehrlichiosis, 1 with an adenoma of perianal glands, 1 with lyposarchoma, 1 with tibial fracture and 1 with a subcutaneous abscess) were used to check if the TR-IFMA developed was able to detect inflammation in dogs in clinical practice.

\subsection{Whole blood and saliva samples}

To compare haptoglobin concentrations in whole blood and serum, EDTA-whole blood samples from 18 dogs ( 8 healthy and 10 with different pathological processes) and their corresponding sera were measured by the TR-IFMA. Additionally, to evaluate potential relationships between $\mathrm{Hp}$ levels in saliva and serum, 18 saliva specimens ( 8 from healthy dogs and 10 from sick ones) and their corresponding sera were tested by the TR-IFMA and their Hp concentrations were compared.

\subsection{Statistics}

The statistical significance level was set at $P=0.05$. Simple regression analysis was performed to compare the results obtained by TR-IFMA and the commercial kit and to compare the $\mathrm{Hp}$ concentration in whole 
blood and serum and in saliva and serum. Hp levels in original and enriched sera with haemoglobin were compared by two-tailed Student $t$ test. Analysis of data was carried out by standard methods with Microsoft Excel 2000.

\section{RESULTS}

\subsection{Isolation of canine $\mathrm{Hp}$}

Canine Hp was purified from acute phase serum by ammonium sulphate fractionation followed by two gel filtration steps. The elution profile of the first gel filtration step appears in Figure 1A. The second peak corresponded mainly to Hp, but it was still contaminated by peak III components as shown by SDS-PAGE (results not shown). The fractions containing higher protein concentration which were further purified, eluted from the column in a single peak (Fig. 1B), which was detected by measuring the absorbance in the collected fractions. The purified protein gave a single band with a molecular size of $52 \mathrm{kDa}$ in SDS-PAGE under nonreducing conditions and, after reduction with 2-mercaptoethanol, two bands of $38 \mathrm{kDa}$ and $17 \mathrm{kDa}$ (Fig. 2) appeared.

\subsection{Precision}

The precision of the TR-IFMA assay is given in Table I. Intra-assay coefficients of variation ranged between $5.7 \%$ and $10.5 \%$, whereas inter-assay precision yielded higher coefficients of variation, which varied between 10.6 and $16.6 \%$.

\subsection{Accuracy}

The dilution of two canine serum samples with high $\mathrm{Hp}$ content resulted in linear regression equations where $x=$ the expected Hp level according to the dilution done and $y=$ the measured Hp level and in which the intercept and slope did not differ from 0 and 1, respectively (Fig. 3).

On measuring 22 serum samples with both methods (TR-IFMA and Phase Hp
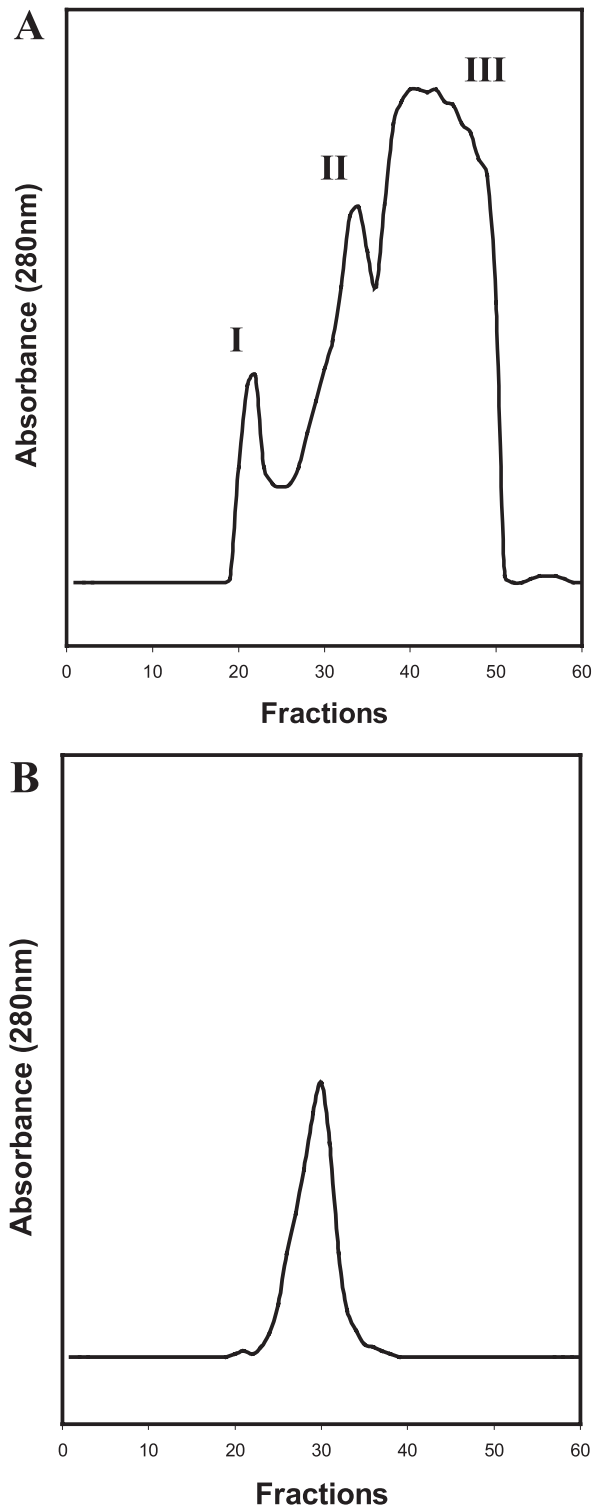

Figure 1. Purification by gel filtration. (A) First gel filtration; (B) Repeat purification of peak II.

assay) the results obtained were highly correlated $\left(R^{2}=0.96\right)$ and the regression equation was $y=1.37 x-0.85$, where $y=$ TRIFMA results $(\mathrm{mg} / \mathrm{mL})$ and $x=$ Phase Hp assay results (mg/mL) (Fig. 4). 


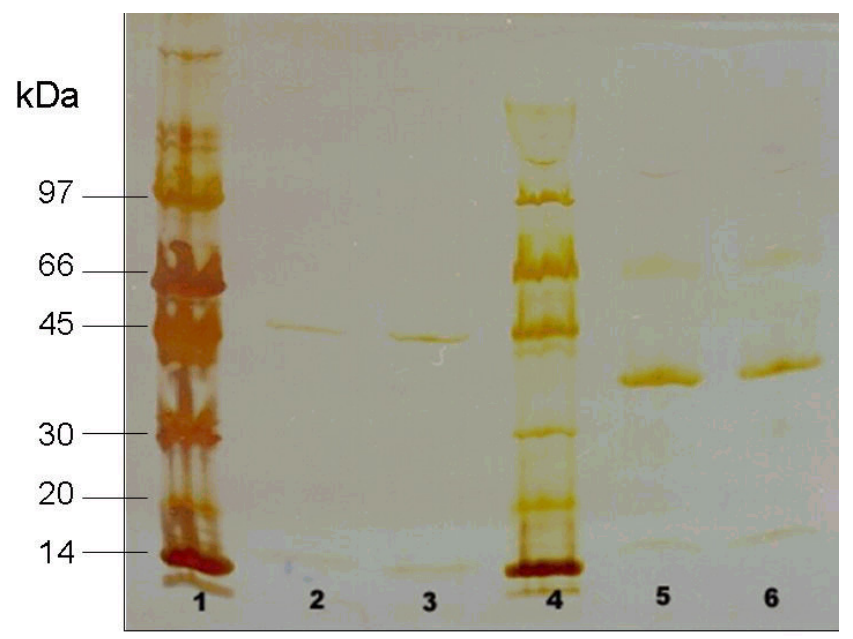

Figure 2. Silver stained SDS-PAGE of canine Hp under non-reducing (lanes 1-3) and reducing (lanes 4-6) conditions (mercaptoethanol, $5 \mathrm{~min}$ at $100{ }^{\circ} \mathrm{C}$ ). Lane 1 and 4: Protein standard (Pharmacia, LMW standard), lane 2: $50 \mu \mathrm{g}$ purified haptoglobin, lane 3: $100 \mu \mathrm{g}$ purified haptoglobin, lane 5: $100 \mu \mathrm{g}$ purified haptoglobin, lane 6: $150 \mu \mathrm{g}$ purified haptoglobin.

\subsection{Limit of detection}

The lowest limit of detection was $0.002 \mu \mathrm{g} /$ $\mathrm{mL}$ corresponding to a signal equal to the mean value plus $3 \mathrm{SD}$ of the zero calibrator.

\subsection{Effect of adding haemolysate}

The presence of increasing amounts of haemoglobin in the sample can be appreciated in the corresponding interferograph (Fig. 5) where data points represent the mean of duplicate determinations, $x$ axes increasing concentrations of haemoglobin,

Table I. Intra and inter-assay precision of the time-resolved immunofluorometric assay for canine Hp.

\begin{tabular}{lccc}
\hline Sample & $\begin{array}{c}\text { Mean Hp } \\
(\mathrm{mg} / \mathrm{mL})\end{array}$ & $\begin{array}{c}\text { Intra-assay } \\
\text { CV\% } \\
(n=10)\end{array}$ & $\begin{array}{c}\text { Inter-assay } \\
\text { CV\% } \\
(n=12)\end{array}$ \\
\hline 1 & 0.51 & 5.7 & 16.6 \\
2 & 2.1 & 2.4 & 10.6 \\
3 & 32.5 & 10.5 & 11.9 \\
\hline
\end{tabular}

and $y$ axes percentage change of haptoglobin for a given concentration of the added substance. Addition of fresh haemolysate to serum samples did not affect haptoglobin concentrations $(P=0.694)$.

\subsection{Clinical study}

Haptoglobin levels in the serum ranged from 0.03 to $1.88 \mathrm{mg} / \mathrm{mL}$ in clinically healthy dogs and between 2.12 and $40.70 \mathrm{mg} / \mathrm{mL}$ in dogs with different pathological processes (Tab. II). Statistical differences $(P<0.003)$ between both groups of animals (healthy and ill dogs) were found.

\subsection{Whole blood and saliva samples}

Comparing the Hp concentrations in whole blood and serum from 18 dogs (Fig. 6), whole blood yielded about $85 \%$ lower values than serum but the measurements from both matrices were related $\left(R^{2}=0.84\right)$. In contrast, the correlation between saliva and serum, which is shown in Figure 7, was weak 


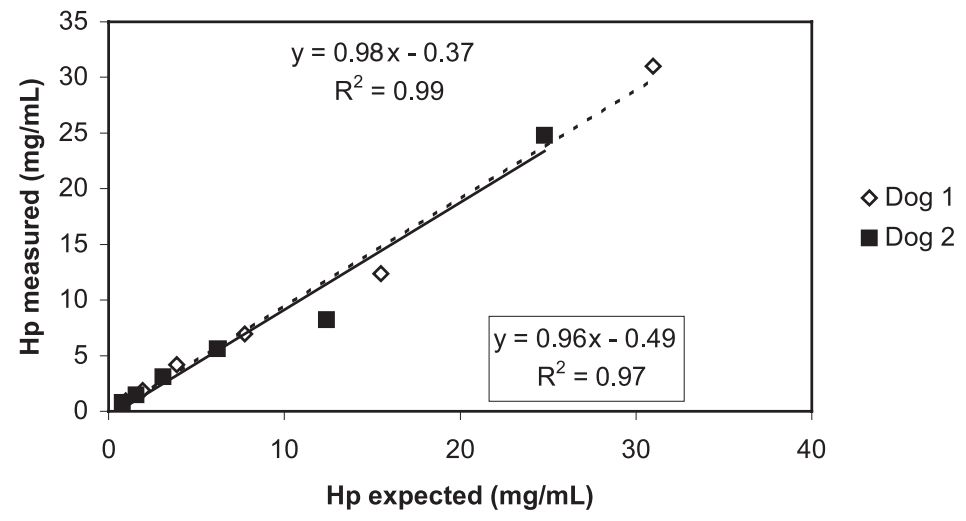

Figure 3. Accuracy of Hp concentrations assessed by dilution of two canine serum samples with high $\mathrm{Hp}$ content. The equation and determination coefficient placed in the box correspond to dog 2 .

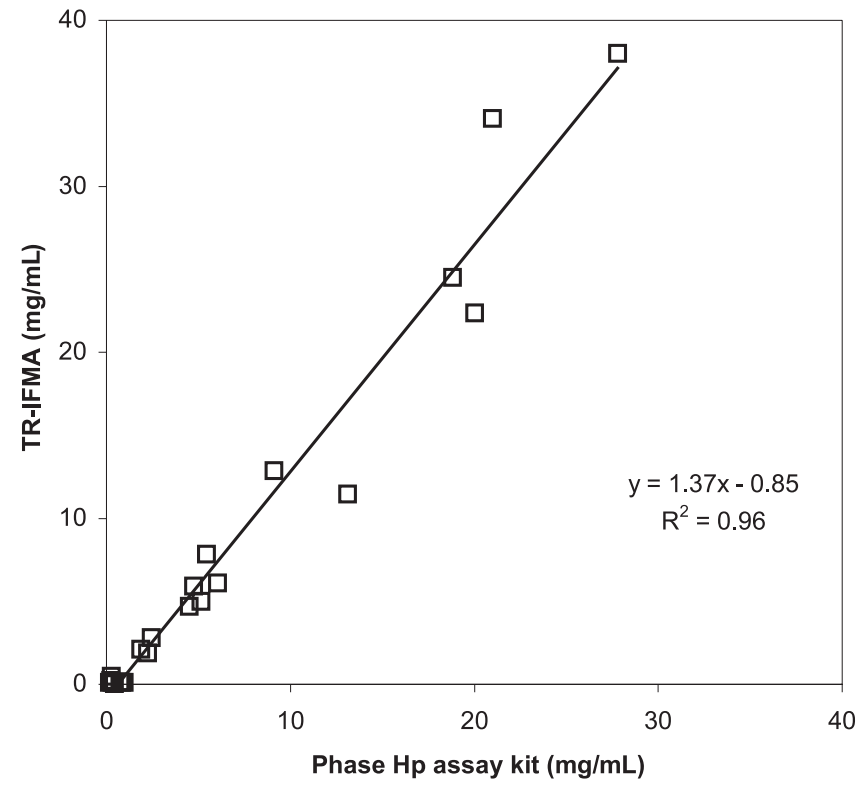

Figure 4. Correlation of canine haptoglobin estimated by TR-IFMA ( $y$ axis) with canine Hp estimated by Phase haptoglobin assay, Tridelta Development Ltd. ( $x$ axis).

$\left(n=18, R^{2}=0.53\right)$. However haptoglobin levels in whole blood $(P<0.026)$ as well as in saliva samples $(P<0.039)$ of healthy dogs were significantly lower than in dogs with pathological processes The ranges of
Hp concentrations in healthy animals were $0.02-0.40 \mu \mathrm{g} / \mathrm{mL}$ for saliva and $0-0.09 \mathrm{mg} /$ $\mathrm{mL}$ for whole blood; and in diseased dogs were $0.28-17.22 \mu \mathrm{g} / \mathrm{mL}$ for saliva and 0.08-2.06 mg/mL for whole blood (Fig. 8). 


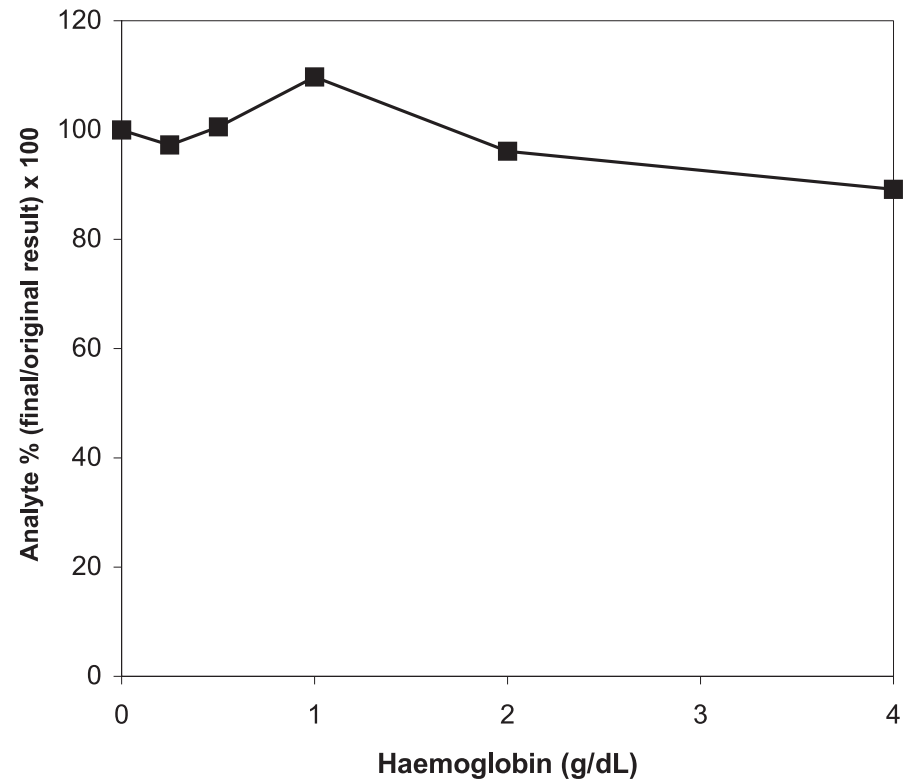

Figure 5. Effect of added haemoglobin on serum haptoglobin determination by TR-IFMA. One hundred percent equals a haptoglobin concentration of $0.42 \mathrm{mg} / \mathrm{mL}$.

Table II. Serum haptoglobin concentrations in healthy dogs and dogs with various diseases by TRIFMA.

\begin{tabular}{lccc}
\hline Number of dogs & Clinical condition & \multicolumn{2}{c}{ Haptoglobin $(\mathrm{mg} / \mathrm{mL})$} \\
\cline { 3 - 4 } & & Median & Range \\
\hline 12 & Healthy & 0.39 & $0.03-1.88$ \\
7 & Leishmaniasis & 20.79 & $2.12-40.7$ \\
3 & Pyometra & 19.36 & $16.39-30.24$ \\
1 & Ehrlichiosis & 6.74 & \\
1 & Adenoma of perianal glands & 3.68 & \\
1 & Lyposarchoma & 8.88 & \\
1 & Tibial fracture & 2.73 & \\
1 & Subcutaneous abscess & 4.2 & \\
\hline
\end{tabular}

\section{DISCUSSION}

Serum haptoglobin concentrations are raised in dogs with a variety of diseases such as polyarthritis [10], leishmaniasis [19], hyperadrenocorticism [7] or neoplasias [20]. The combined determination of the concen- tration of Hp and CRP has been suggested to have the greatest diagnostic value to differentiate between pathological states [7] and therefore serum $\mathrm{Hp}$ assays represent useful tools for the diagnosis, treatment monitoring and prognosis of many pathological processes in dogs. In human medicine, acute 


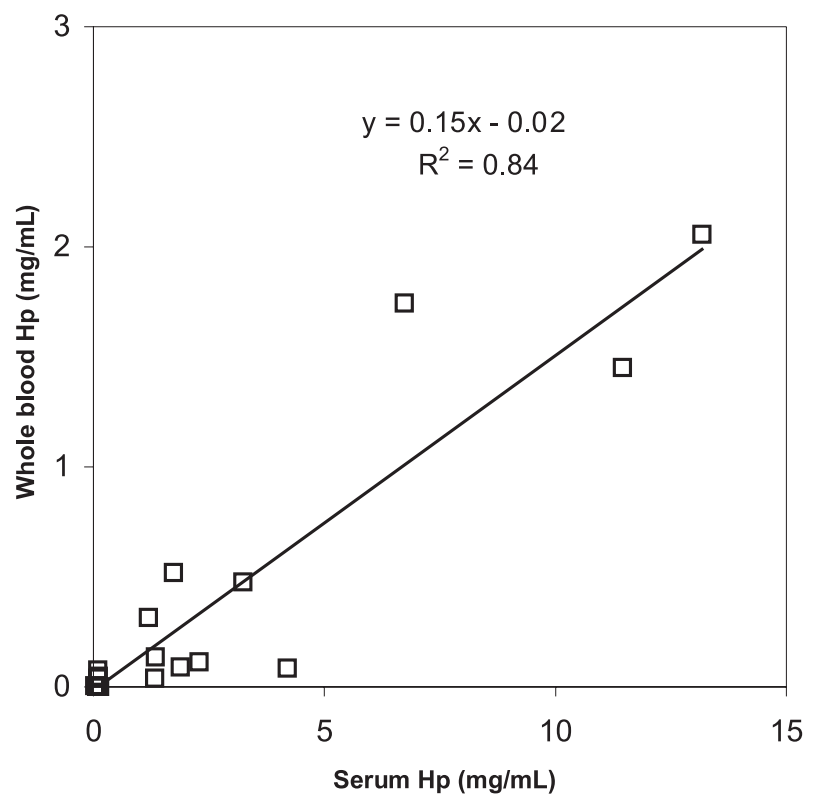

Figure 6. Linear regression of $\mathrm{Hp}$ concentrations $(\mathrm{mg} / \mathrm{mL})$ measured in whole blood and serum by TR-IFMA.

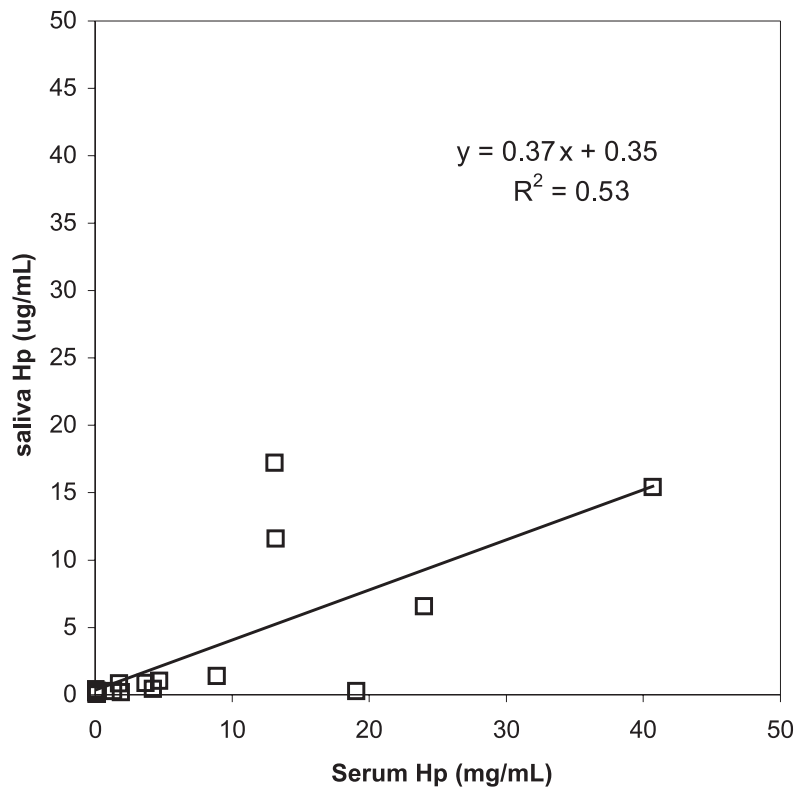

Figure 7. Linear regression of $\mathrm{Hp}$ concentrations measured in saliva $(\mu \mathrm{g} / \mathrm{mL})$ and serum $(\mathrm{mg} / \mathrm{mL})$ by TR-IFMA. 


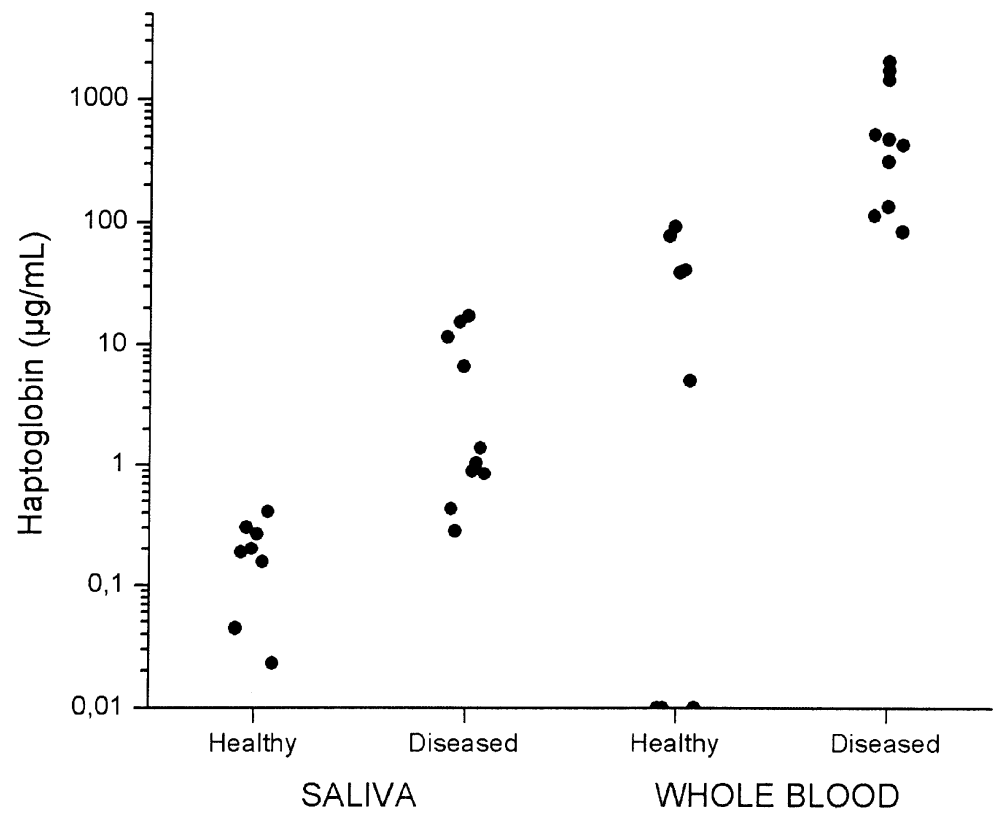

Figure 8. Haptoglobin levels $(\mu \mathrm{g} / \mathrm{mL})$ in whole blood and saliva from healthy $(n=8)$ and diseased $(n=10)$ dogs by TR-IFMA (the whole blood Hp concentration in 3 of the healthy dogs was undetectable).

phase proteins have been extremely valuable markers of disease for decades, but their use in veterinary medicine has been limited due to a lack of available commercial tests, quality control material and knowledge on the interpretation of the data [8]. However in the last few years, numerous studies have been carried out in companion animal medicine $[7,8,19,23]$ and in production animals [28, 29]. For instance Hp has been measured in meat juice from pigs at slaughter opening new and intriguing possibilities for the assessment of animal health in animal production [14] and haptoglobin measurement in milk samples from cows has been demonstrated to be useful in diagnosing mastitis [24].

We herein report the development of a time-resolved immunofluorometric assay for the determination of haptoglobin in dog specimens.
The idea of purifying canine Hp by using a combination of ammonium sulphate precipitation and gel filtration on a Superdex 200 column was based on a previous paper [39] in which porcine Hp was purified by ammonium sulphate precipitation followed by gel permeation chromatography. The canine protein showed a molecular mass of $52 \mathrm{kDa}$ in the absence of mercaptoethanol, and under reducing conditions two bands of 38 and $17 \mathrm{kDa}$ appeared, agreeing with previous reports $[22,35]$. This purification strategy involved fewer chromatographic separations than the methods detailed previously $[5,30]$, reducing the time taken to purify $\mathrm{Hp}$ to an acceptable level so this procedure could be widely used for the purification of canine $\mathrm{Hp}$. Stability of the purified protein is one problem to be solved, since we have noticed that after a few weeks of storage the protein loses its reactivity. Additional studies should 
be required to discover the possible factors affecting Hp stability.

Coefficients of variation of the assay were slightly higher than the ones provided by the commercially available haptoglobin kit (Tridelta Development Ltd., Ireland) and other authors [10, 20, 31]. Usually, immunoassays of in vitro clinical chemistry allow a maximum $\mathrm{CV}$ of $15 \%$ and even of $20 \%$ for samples with very low concentration [13]. In addition, the clinical study results indicate that the assay is useful in differentiating dogs suffering from inflammatory processes and healthy dogs and concentrations measured in these animals were within the ranges reported previously from others $[10,17,20]$. However, one false-negative result appeared when measuring saliva specimens and also with whole blood samples from diseased animals, so further studies with a higher amount of this type of samples would be indicated to determine the test sensitivity and specificity.

The assay range of the present technique was broader ( 0.01 to $10 \mu \mathrm{g} / \mathrm{mL})$ than the one supplied by the commercial kit and other methods [10,17].

The assay was accurate when diluting serum samples and when comparing results obtained by TR-IFMA with the ones supplied by the commercial kit.

The high sensitivity of the assay is its most remarkable feature. The limit of detection obtained with this method $(0.000002 \mathrm{mg} /$ $\mathrm{mL}$ ) is much lower than the one reported by other authors [10] or by the commercial kit $(0.05 \mathrm{mg} / \mathrm{mL})$. This fact has allowed quantification of Hp not only in whole blood but also in saliva. This enhanced sensitivity is to be expected since in the immunoassay there is a direct measure of $\mathrm{Hp}$ by specific antibody whereas in the Hp binding assay, peroxidase activity can be affected by a number of factors. These include the presence of haemoglobin (from lysed red cells), active and inactive forms of $\mathrm{Hp}$ [2], the presence of serum peroxidase inhibitors such as cysteine and glutathione, and the presence in the serum of proteins with peroxidase activity.

In an assay based on peroxidase activity [10], an immunoturbidimetric assay [38] and in a porcine ELISA [28], haemoglobin caused a fall in $\mathrm{Hp}$ results and therefore haemolysed samples should be avoided. Thus, one of the main advantages of the immunoassay described in this paper over the traditional methods would be that whole blood and haemolysed serum specimens might be used, since the presence of free haemoglobin from haemolysate does not seem to interfere with the detection of target analyte.

Some analyte concentrations such as human [34] and canine [26] CRP or creatine kinase [36] are lower in whole blood samples than in serum or plasma samples due to the volume taken by red cells. The observation that $\mathrm{Hp}$ concentrations in whole blood were much lower than in serum could be partially attributed to this fact. Likewise certain blood components could inhibit the antigen-antibody binding in the Hp assay or even other unknown factors might be responsible for the decrease in Hp levels in whole blood. Further studies should be carried out to clarify this subject.

The option of measuring haptoglobin in saliva for practical purposes can have several advantages. Saliva sampling is a noninvasive method and therefore less stressful for the animal. Additionally, on account of the facility of collecting the salivary sample (the application of the sponge is generally well accepted by the dog), the dog owners can do it themselves at home. This could be interesting for people who live far away from veterinary centres or for dogs which are not used for transportation. The sensitivity of the present TR-IFMA allowed the quantification of Hp in saliva, however our results showed a poor correlation between Hp levels in saliva and serum. Recently a similar result was obtained when porcine haptoglobin was measured in saliva specimens [14]. The low coefficient of regression obtained may be explained by a small delay 
in haptoglobin coming from blood to saliva or by other factors affecting saliva secretion such as: plasma composition, flow rate, circadian and circannual rhythms, exercise, drugs, antigenic stimulation or various diseases [4]. Nevertheless it should be pointed out that Hp levels in healthy dogs were significantly lower than in dogs with pathological processes, even so further clinical studies with a higher number of samples, especially from diseased animals should be performed to assess the possible future applicability of saliva samples in Hp measurements.

Overall, it can be concluded that the TRIFMA method described in this paper, due to its high sensitivity and accuracy, represents a very valuable system for the measurement of haptoglobin in canine serum, whole blood and saliva specimens, offering a suitable alternative to traditional methods of determining haptoglobin.

\section{REFERENCES}

[1] Aggerbeck H., Norgaard-Pedersen B., Heron I., Simultaneous quantitation of diphtheria and tetanus antibodies by double antigen, time-resolved fluorescence immunoassay, J. Immunol. Methods 190 (1996) 171-183.

[2] Cerda S., Oh S.K., Methods to quantitate human haptoglobin by complexation with hemoglobin, J. Immunol. Methods 134 (1990) 51-59.

[3] Conner J.G., Eckersall P.D., Acute phase response in the dog following surgical trauma, Res. Vet. Sci. 45 (1988) 107-110.

[4] Dawes C., Considerations in the development of diagnostic tests on saliva, Ann. NY Acad. Sci. 294 (1993) 265-269.

[5] Dobryszycka W., Elwyn D.H., Kukral J.C., Isolation and chemical composition of canine haptoglobin, Biochim. Biophys. Acta 175 (1969) 220-222.

[6] Eckersall P.D., Acute phase proteins as markers of inflammatory lesions, Comp. Haematol. Int. 5 (1995) 93-97.

[7] Eckersall P.D., C-reactive protein and haptoglobin, markers of infection, inflammation, hyperadrenocorticism and stress in dogs, Vet. Clin. Pathol. 32 (2003) 154.
[8] Eckersall P.D., The time is right for acute phase protein assays, Vet. J. 168 (2004) 3-5.

[9] Eckersall P.D., Conner J.G., Bovine and canine acute phase proteins, Vet. Res. Commun. 12 (1988) 169-178.

[10] Eckersall P.D., Duthie S., Safi S., Moffatt D., Horadagoda N.U., Doyle S., Parton R., Bennett D., Fitzpatrick J.L., An automated biochemical assay for haptoglobin: prevention of interference from albumin, Comp. Haematol. Int. 9 (1999) 117-124.

[11] Erkens J.H.F., Dieleman S.J., Dressendörfer R.A., Strasburger C.J., A time-resolved fluoroimmunoassay for cortisol in unextracted bovine plasma or serum with optimized procedures to eliminate steroid binding protein interference and to minimize non-specific streptavidin-europium binding, J. Steroid. Biochem. Mol. Biol. 67 (1998) 153-161.

[12] Fiet J., Boudi A., Giton F., Villette J.M., Boudu Ph., Soliman H., Morineau G., Galons H., Plasma 21-deoxycortisol: comparison of a time-resolved fluoroimmunoassay using a biotinylated tracer with a radioimmunoassay using 125 iodine, J. Steroid. Biochem. Mol. Biol. 72 (2000) 55-60.

[13] Guidance for Industry, Bioanalytical Method Validation, US Department of Health and Human Services, Food and Drug Administration, Center for Drug Evaluation and Research (CDER), Center for Veterinary Medicine (CVM), May 2001.

[14] Hiss S., Knura-Deszczka S., Regula G., Hennies M., Gymnich S., Petersen B., Sauerwein H., Development of an enzyme immuno assay for the determination of porcine haptoglobin in various body fluids: testing the significance of meat juice measurements for quality monitoring programs, Vet. Immunol. Immunopathol. 96 (2003) 73-82.

[15] Kimura H., Mukaida M., Wang G., Yuan J., Matsumoto K., Dual-label time-resolved fluoroimmunoassay of psychopharmaceuticals and stimulants in serum, Forensic Sci. Int. 113 (2000) 345-351.

[16] Kurosky A., Kim H., Touchstone B., Comparative sequence analysis of the n-terminal region of rat, rabbit, and dog haptoglobin $\beta$-chains, Comp. Biochem. Physiol. B55 (1976) 453459 .

[17] Klein H.J., Gross D.M., O’beirne A.J., Nolan T.E., Adaptation of a fluorescent immunoassay for canine haptoglobin, Cornell Vet. 77 (1987) 21-32. 
[18] Laemmli U.K., Cleavage of structural proteins during the assembly of the head of bacteriophage T4, Nature 227 (1970) 680-685.

[19] Martínez-Subiela S., Bernal L.J., Cerón J.J., Serum concentrations of acute phase proteins in dogs with leishmaniasis during short-term treatment, Am. J. Vet. Res. 64 (2003) 10211026.

[20] McGrotty Y.L., Knottenbelt C.M., Ramsey I.K., Reid S.W.J., Eckersall P.D., Haptoglobin concentrations in a canine hospital population, Vet. Rec. 152 (2003) 562-564.

[21] McNair J., Elliott C.T., Mackie D.P., Development of a sensitive and specific time resolved fluorometric immunoassay for the bovine acute phase protein haptoglobin (Hp), J. Immunol. Methods 184 (1995) 199-205.

[22] Mominoki K., Nakagawa-Tosa N., Morimatsu M., Syuto B., Saito M., Haptoglobin in Carnivora: a unique molecular structure in bear, cat and dog haptoglobins, Comp. Biochem. Physiol. B110 (1995) 785-789.

[23] Murata H., Shimada N., Yoshioka M., Current research on acute phase proteins in veterinary diagnosis: an overview, Vet. J. 168 (2004) 28-40.

[24] Nielsen B.H., Jacobsen S., Andersen P.H., Niewold T.A., Heegaard P.M., Acute phase protein concentrations in serum and milk from healthy cows, cows with clinical mastitis and cows with extramammary inflammatory conditions, Vet. Rec. 154 (2004) 361-365.

[25] Parra M.D., Bernal L.J., Cerón J.J., Cortisol and free thyroxine determination by timeresolved fluorometry in canine serum, Can. J. Vet. Res. 68 (2004) 98-104.

[26] Parra M.D., Tuomola M., Cabezas-Herrera J., Cerón J.J., Use of a time-resolved immunofluorometric assay for canine C-reactive protein measurement in whole blood samples, Am. J. Vet. Res. (in press).

[27] Peruski A.H., Johnson L.H., Peruski L.F., Rapid and sensitive detection of biological warfare agents using time-resolved fluorescence assays, J. Immunol. Methods 263 (2002) 35-41.

[28] Petersen H.H., Nielsen J.P., Heegaard P.M.H., Evaluation of an Enzyme Linked ImmunoSorbent Assay (ELISA) for determination of porcine haptoglobin, J. Vet. Med. A Physiol. Pathol. Clin. Med. 48 (2001) 513-523.

[29] Petersen H.H., Nielsen J.P., Heegaard P.M.H., Application of acute phase protein measurements in veterinary clinical chemistry, Vet. Res. 35 (2004) 163-187.
[30] Shim B., Yoon C., Oh S., Lee T., Kang Y., Studies on swine and canine serum haptoglobins, Biochim. Biophys. Acta 243 (1971) 126136.

[31] Solter P.F., Hoffmann W.E., Hungerford L.L., Siegel J.P., St. Denis S.H., Dorner J.L., Haptoglobin and ceruloplasmin as determinants of inflammation in dogs, Am. J. Vet. Res. 52 (1991) 1738-1742.

[32] Soukka T., Paukkunen J., Harma H., Lonnberg S., Lindroos H., Lövgren T., Supersensitive time-resolved immunofluorometric assay of free prostate-specific antigen with nanoparticle label technology, Clin. Chem. 47 (2001) 1269-1278.

[33] Stenman J., Alfthan H., Stenman U., Streptavidin-biotin based time-resolved immunofluorometric assay for direct measurement of high concentrations of human chorionic gonadotropin (hCG), J. Immunol. Methods 175 (1994) 161-167.

[34] Tarkkinen P., Palenius T., Lövgren T., Ultrarapid, ultrasensitive one-step kinetic immunoassay for c-reactive protein (CRP) in whole blood samples: measurement of the entire CRP concentration range with a single sample dilution, Clin. Chem. 48 (2002) 269-277.

[35] Tosa N., Morimatsu M., Nakagawa M., Miyoshi F., Uchida E., Niiyama M., Syuto B., Saito M., Purification and identification of a serum protein increased by anthelmintic drugs for Dirofilaria immitis in dogs, J. Vet. Med. Sci. 55 (1993) 27-31.

[36] Tuomola M., Vainio J., Lövgren T., Rapid time-resolved immunofluorometric assay for the measurement of creatine kinase in serum and whole blood samples, J. Agric. Food Chem. 50 (2002) 6659-6662.

[37] Uehara M., Lapcik O., Hampl R., Al-Maharik N., Makela T., Wähälä K., Mikola H., Adlercreutz $\mathrm{H}$., Rapid analysis of phytoestrogens in human urine by time-resolved fluoroimmunoassay, $\mathrm{J}$. Steroid. Biochem. Mol. Biol. 72 (2000) 273 282.

[38] Wiedmeyer C.E., Solter P.F., Validation of human haptoglobin immunoturbidimetric assay for detection of haptoglobin in equine and canine serum and plasma, Vet. Clin. Pathol. 25 (1996) 141-146.

[39] Yang S.J., Mao S.J.T., Simple high-performance liquid chromatographic purification procedure for porcine plasma haptoglobin, J Chromatogr. B Biomed. Sci. Appl. 731 (1999) 395-402. 